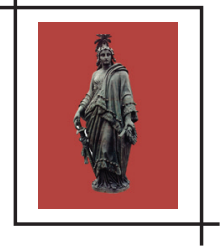

\title{
BERGSON E A LIBERDADE
}

\section{Regina Rossetti ${ }^{1}$}

\begin{abstract}
Resumo: Pretende-se, neste texto, a partir do último capitulo do Ensaio sobre os dados imediatos da consciência, de Henri Bergson, que, segundo o próprio autor, a tradição filosófica denomina de problema da liberdade, apresentar algumas reflexões sobre como ele pretende refutar o determinismo, e por se tratar de um ensaio que aborda uma ciência particular, a psicologia, o determinismo aqui combatido é o psicológico. Bergson polemiza com a psicofísica de sua época e afirma que a liberdade é um fato e não um problema. Em síntese, a liberdade e os problemas relacionados a ela estão ligados a uma consideração errônea da concepção de tempo, o que nos leva a considerar os estados de consciência como homogêneos e separados. Essa concepção propõe que a liberdade está no eu que dura e a necessidade, na natureza que não dura, enfim, tais noções estão na base da resolução dos problemas relacionados à liberdade.
\end{abstract}

Palavras-chave: Liberdade. Tempo. Determinismo. Psicologia. Necessidade.

\section{INTRODUÇÃO}

No último capítulo do Ensaio sobre os dados imediatos da consciência, Bergson trata daquilo que a tradição filosófica chamou de problema da liberdade. Grande parte do esforço do Ensaio dirige-se a refutar o determinismo, e como se trata de um ensaio que fala de uma ciência particular, a psicologia, o determinismo aqui combatido é o psicológico. Bergson polemiza com a psicofísica de sua época e afirma que a liberdade é um fato e não um problema. A essência da vida interior é temporal, todavia, não é assim que, no geral, a psicologia de seu tempo a entendeu; marcada pelo determinismo psicofísico, acabou por não reconhecer a verdadeira natureza psíquica, ao confundi-la com o físico, entendendo-a como de natureza espacial. Essa concepção propõe que a liberdade está no eu que dura e a necessidade, na natureza que não dura. A noção de causalidade inclui o conceito de possibilidade, ou seja, uma causa teria vários efeitos possiveis. Há aqui a ideia de força e podemos chamar 
essa causalidade de causalidade dinâmica; nela o futuro só existe no presente, na forma de ideia, e é preciso esforço para realizar-se. As coisas durariam como nós e, assim, haveria uma mesma duração tanto para os fatos físicos quanto para os psicológicos. $E_{1}$ mais ainda, a liberdade estender-se-ia até os fenômenos da natureza por meio da contingência. Demonstrar que o problema da liberdade é, na verdade, um falso problema é um dos propósitos do primeiro livro de Bergson, Ensaio sobre os dados imediatos da consciência.

\section{LINHAS GERAIS DO PENSAMENTO BERGSONIANO}

0 tempo é o principal tema do pensamento do filósofo francês Henri Bergson. Constante no conjunto de sua obra, o tempo é compreendido como duração psicológica no Ensaio sobre os dados imediatos da consciência, como tempo criador na Evolução criadora e como memória ontológica em Matéria e memória. Para Bergson, tempo é duração, ou seja, o movimento constante e contínuo de mudanças essenciais. Não há a imobilidade; por trás do movimento há somente movimento, ou seja, por trás das coisas que mudam há uma essência que é, ela própria, movimento também. Devemos estar atentos à radicalidade da visão bergsoniana de realidade, para a qual não há imobilidade nem na superfície nem na essência. Nesse mesmo sentido, não há a coisa que muda, há somente a mudança, porque "a coisa", toda ela, é movimento. Deriva daí o significado sutil, para Bergson, da palavra movente, que, muito mais do que ser a qualidade daquilo que se move ou está em movimento, significa aquilo que é movimento; algo movente é aquilo que, em sua essência e totalidade, é movimento. 0 pensamento bergsoniano é inovador na tradição porque pensa uma essência que não é aquilo que permanece, mas é aquilo que muda constantemente. Bergson chama a esse movimento essencial da realidade de duração. Para ele, a realidade é essencialmente movente e sua filosofia "considera a duração como a própria substância da realidade" (BERGSON, 1971, p. 269). Sendo a substância a mesma da realidade, o movimento não possui um suporte imutável que permanece sempre o mesmo, sobre o qual se acrescentaria, vindo de fora, o movimento. 0 que há é a mudança, mas não há sob a mudança coisas estáticas que mudam.

0 movimento encontra-se por toda parte, da essência à superfície, do espírito à matéria, do eu ao Universo; tudo dura, muda, transforma-se constantemente. Para Bergson (1938, p. 167), a totalidade da realidade é movente e o movimento é o próprio substrato dessa realidade, "a mudança é real e mesmo constitutiva da realidade". 0 real é um fluxo contínuo de mudanças, um movimento indivisivel e substancial, imanente a si mesmo numa duração que se prolonga sem fim. Portanto, a essência da realidade é movimento e esse movimento essencial é a duração - palavra-chave do pensamento bergsoniano. Logo, sempre que falarmos em duração, estaremos falando da essência movente; essência que é movimento. Assim, este estudo parte de uma noção clara de realidade: uma realidade movente, cuja essência é 
a duração, a mudança, o movimento. Coerente com sua visão de realidade, filosofar para Bergson é aprofundar-se nesse devir universal, que é a própria realidade, por meio do próprio movimento interior, quando o espírito regressa a si mesmo em busca do princípio movente. "A filosofia não é apenas o regresso do espírito a si mesmo, a coincidência da consciência humana com o princípio vivo de onde emana, uma tomada de contato com o esforço criador. É aprofundamento do devir geral" (BERGSON, 1971, p. 353). Filosofar é entrar em contato com a duração real, que é a essência da realidade, contato esse que somente a intuição pode nos dar. Assim, da existência desse movimento essencial podemos ter certeza quando com ele tomamos contato por meio da intuição, quando coincidimos com o movimento da realidade e podemos acompanhar seus contornos. Além disso, a intuição é conhecimento interior e capta o movimento em sua totalidade; logo, ela sempre nos dará uma visão do Todo. Se queremos saber o que são Movimento e Totalidade, temos primeiro que determinar qual é o método para alcançar essa sabedoria, e é por isso que partimos de um estudo sobre a intuição. Portanto, o objetivo da filosofia de Bergson é a intuição da duração, que é a essência da realidade movente.

Demonstrar que o problema da liberdade é na verdade um falso problema é um dos propósitos do primeiro livro de Bergson, Ensaio sobre os dados imediatos da consciência. Nele, o filósofo distingue entre o tempo duração e o tempo espacial. A duração é o tempo que passa incessante e contínuo, é a própria essência da realidade; tempo real que dura e que passa continuamente transformando tudo, sendo ele próprio mudança. 0 outro tempo, o espacial, é um tempo ilusório; originário da confusão entre tempo e espaço - também chamado por Bergson de tempo homogêneo - é apenas o espaço camuflado de tempo. Trata-se no Ensaio de mostrar que somente a duração é a essência do tempo real e que o tempo cientificamente conhecido é, em sua realidade última, espaço.

0 Ensaio não trata do tempo em geral, mas de sua forma privilegiada de acesso: o tempo interno, vivido no interior de nossa consciência. A abordagem do tema parte da análise crítica da psicologia determinista da época. Esse objetivo crítico de Bergson pode ser observado pela própria organização dessa obra. Em seu primeiro capítulo, trata de mostrar que a intensidade dos estados psicológicos não pode ser mensurável, e se entendemos essa intensidade como uma grandeza é porque confundimos qualidade com quantidade. No segundo capítulo, demonstra que esses mesmos estados, agora tomados em sua multiplicidade, não podem formar uma soma numérica, e se concebemos esta multiplicidade interior como quantitativa é porque confundimos o tempo interno com o espaço exterior. No terceiro capítulo, Bergson trata da liberdade e pode demonstrar a não verdade de uma teoria psicológica fundada no determinismo, que concebe a vida psíquica como mensurável e semelhante ao número. Dessa forma, todo o Ensaio constitui um estudo a respeito do tempo em sua expressão psíquica, abordada no sentido de refutar o determinismo psicológico e instaurar a liberdade como um fato. 


\section{A LIBERDADE EM BERGSON}

No último capítulo do Ensaio, Bergson (1988) trata do problema da liberdade, que segundo o filósofo é uma questão comum na metafísica e na psicologia. Grande parte do esforço do Ensaio pretende refutar o determinismo, e como se trata de um texto que fala de uma ciência particular, a psicologia, o determinismo aqui combatido é o psicológico. A essência da vida interior é temporal, todavia, não é assim que, no geral, a psicologia de seu tempo a entendeu; marcada pelo determinismo psicofísico, acabou por não reconhecer a verdadeira natureza psíquica, ao confundi-la com o físico, entendendo-a como de natureza espacial. Passemos, agora, a tratar as principais teses do determinismo psicológico e a crítica que Bergson faz a cada uma delas.

Primeiro, o determinismo psicológico afirma a tese do paralelismo entre o psíquico e o cerebral. Procura provar que para cada estado cerebral corresponderia um estado psicológico por ele determinado. Nossos sentimentos, sensações e ideias seriam resultantes mecânicas dos movimentos dos átomos cerebrais, tornando-se previsíveis. Podemos encontrar por trás da tese paralelista a mesma assimilação do tempo ao espaço, ideia rejeitada por Bergson e que serve de concepção filosófica geral de fundamentação da ciência determinista. A tese paralelista confunde corpo e alma, matéria e espírito e não admite que a consciência não depende do cérebro para existir. Essa tese é detalhadamente analisada e refutada, em Matéria e memória, trabalho posterior ao Ensaio, por meio da demonstração de que a vida psíquica é independente do sistema corporal.

Assim, o determinismo baseia-se na lei de conservação de energia: a quantidade total de energia e de matéria de um sistema permanece sempre constante independentemente do tempo e de transformações. Assegura como consequência a determinação, a previsão e a reversibilidade, não somente dos fenômenos físicos, mas de todos os fenômenos, já que se pretende a energia universal. Todavia, quanto se trata de fenômenos psíquicos surgem dificuldades. Isso porque é impossivel aplicar a lei de conservação de energia ao domínio da vida e da consciência porque nesta o passado acumula-se, e o tempo, que sempre avança, é um ganho para o ser vivo e consciente. Se há ganho, quando falamos de vida e consciência, estamos falando em criação, em invenção, portanto, estamos falando em aumento de energia. A vida e a consciência, por desenrolarem-se na pura duração criadora, escapam à lei de conservação de energia que, portanto, não é universal como se pretendia². 0 determinismo psicológico comete o erro de tentar aplicar tal lei aos fatos psicológicos porque identifica a duração vivida e real com o sistema conservador do espaço no mundo exterior, cuja matéria

2 - "É apenas a transposição indevida das condições do sistema material para a vida da consciência. Dai deriva a extensão da lei de conservação para a realidade psíquica e o determinismo psicológico, negação da liberdade" (LEOPOLDO E SILVA, 1994, p. 158). 
inerte está sempre num presente eterno e cujo tempo não representa nem acréscimo nem perda, esquecendo-se de que a vida psíquica é criação.

Terceiro, o determinismo psicológico aplica a lei de causalidade à vida psíquica, ou seja, os estados psicológicos são tratados pelo sistema de causa e efeito. Para o psicólogo determinista todo ato está determinado pelo estado psíquico antecedente porque submetido à lei de causalidade como todos os fenômenos da natureza. Por essa lei todo fenômeno é determinado pelas suas condições e uma causa deve produzir sempre o mesmo efeito. Mas, se pensarmos os fatos psíquicos na sua pura duração, veremos que a lei de causalidade física não se aplica a eles. Isso porque os fatos psicológicos profundos são radicalmente heterogêneos e únicos, pois constituem momentos diferentes na história da vida psíquica. Assim, uma mesma causa interna nunca pode se apresentar duas vezes na consciência, porque não podem existir duas "causas" iguais. É bom observar que a refutação bergsoniana do princípio de causalidade determinista é profunda no sentido de que não se trata, apenas, da impossibilidade da "mesma causa" não produzir "os mesmos efeitos", mas sendo cada causa única e não havendo repetição sequer pode existir a "mesma" causa.

Se existe uma relação de causa entre os fatos internos, ela não tem nada a ver com aquilo que os físicos chamam de causalidade na natureza, ao contrário, sua essência seria de ordem psicológica. Segundo Bergson: "Para o físico, a mesma causa produz sempre o mesmo efeito; para o psicólogo [...] uma causa interna profunda produz o seu efeito uma vez, e nunca mais o produzirá" (BERGSON, 1988, p. 139). Isso porque o eu dura e muda a todo instante e cada estado psicológico é único. Cada causa é única e produz um único efeito e nunca mais se apresentará de novo. Somente no sentido de causa única podemos dizer que existe uma causalidade psicológica. Assim, é necessário distinguir duas concepções diferentes de causalidade, uma física e outra psicológica. É necessário separar a causalidade externa puramente matemática, da causalidade interna que possui a ideia de força psíquica da qual emana o ato livre. Como diz Bergson (1988, p. 150):

\footnotetext{
[...] a relação de causalidade interna é puramente dinâmica e não tem nenhuma analogia com a relação de dois fenômenos exteriores que se condicionam. É que estes, sendo suscetiveis de se reproduzirem no espaço homogêneo, entrarão na composição de uma lei, ao passo que os fatos psíquicos profundos se apresentam à consciência uma vez, e nunca mais voltarão.
}

Para tanto, Bergson realiza uma detalhada análise do problema identificando vários tipos de causalidade.

A primeira é a noção de causalidade entendida como determinação necessária; nela, o futuro está totalmente dado no presente na forma de uma preexistência matemática. Esta é a causalidade da física e afirma que as coisas não duram como nós. Temos aqui uma concep- 
ção de realidade que exclui os estados da consciência e na qual os fenômenos físicos são determinados exatamente porque não duram como nós. Essa concepção propõe que a liberdade está no eu que dura e a necessidade, na natureza que não dura. A segunda noção de causalidade inclui o conceito de possibilidade, ou seja, uma causa teria vários efeitos possíveis. Há aqui a ideia de força e podemos chamar essa causalidade de causalidade dinâmica. Nela o futuro só existe no presente, na forma de ideia, e é preciso esforço para realizar-se. As coisas durariam como nós e, assim, haveria uma mesma duração tanto para os fatos físicos quanto para os psicológicos. E, mais ainda, a liberdade estender-se-ia até os fenômenos da natureza por meio da contingência.

Portanto, Bergson não retira da vida interior a noção de causa, mas essa noção não tem nada a ver com a ideia de causalidade mecanicista, para a qual não se pode encontrar no efeito nada além do que já existia na causa. Causa psicológica, para o filósofo, deve ser entendida como a ligação de um estado a outro estado psíquico que o engendrou, e no "efeito" pode-se encontrar muito mais do que havia na causa. Segundo Gouhier (1989, p. 46, tradução nossa), citando uma carta de Bergson à Léon Brunschvicg: "[...] e como isso (a causalidade física) implica que nada é criado na passagem de um momento para o outro, este (a causalidade psicológica) implica, pelo contrário, a criação pelo próprio ato de algo que não existia nos antecedentes." Bergson introduz, assim, na noção de causalidade psicológica, uma espécie de causalidade criadora, livre, imprevisível, muito distinta da ideia determinista de causalidade física. Para evitar confusões com o sentido mecanicista e tradicional do termo causa, melhor seria falar-se em motivação. Nesse sentido, um estado psíquico teria um motivo, como algo que o moveu, mas não o determinou. Um motivo único que somente pode ser conhecido por um olhar retrospectivo, pois não se pode prever o estado posterior de certo motivo, pois pode intervir aí a criação, a partir da qual podem surgir novos estados imprevisiveis.

Sustentando o determinismo psicológico, há uma concepção associacionista do espírito. Conforme Hude (1990, p. 129; tradução nossa), "o determinismo psicológico assume a concepção associacionista da vida psíquica: é para esse associacionismo que os estados de consciência são numericamente múltiplos e mensuráveis." Para o determinismo psicológico, a vida psíquica é considerada uma associação de estados psicológicos separados uns dos outros em que se introduz a ideia de causalidade, o que nos leva a afirmar como absoluta a determinação dos fatos da consciência uns pelos outros. A concepção associacionista procede dessa maneira em razão de sua visão distorcida da realidade psicológica e da duração. Concebe o eu

3 - "[...] et puisque celle-ci (la causalité physique) implique que rien ne se crée dans le passage d'un moment au moment suivant, celle-là (la causalité psychologique) implique au contraire la création par l'acte lui même de quelque chose qui n'existait pas dans les antécédents".

4 - "Le déterminisme psychologique suppose la conception associationiste de la vie psychique: c'est pour cet associationnisme que les états de conscience sont numériquement multiples et mesurables". 
como uma multiplicidade de justaposição dos estados da consciência ocorrendo numa duração homogênea ${ }^{5}$. Um agregado de estados psíquicos, cujos conflitos, por exemplo, somente se resolveriam pela vitória do estado mais forte. Não percebem que o eu, ao hesitar entre dois sentimentos aparentemente contrários, vai de um ao outro, modificando-os a todo instante porque estão intimamente ligados e, assim, se reforçam mutuamente, levando o eu ao ato livre por uma evolução natural. Portanto, em sua realidade essencial, a duração pura, os estados psíquicos não estão separados, pelo contrário, estão intimamente interligados e organizados de forma livre; e é exatamente essa organização dinâmica e livre dos estados da consciência que impede a determinação psicológica defendida pelos associacionistas.

Assim, Bergson refuta todo determinismo psicológico, derrubando seus principais pilares: o paralelismo psíquico, a lei de conservação de energia, a lei de causalidade aplicada à vida interior e a visão associacionista do espírito; mostrando que a vida psíquica é criação livre e imprevisivel de novos estados que se sucedem no ritmo próprio da duração interna que constitui sua essência. Esse determinismo psicológico serviu de fundamento à psicofísica, que confundindo o tempo vivido pelo eu em sua interioridade qualitativa - a duração psicológica - com o espaço exterior onde as coisas materiais se justapõem numa multiplicidade quantitativa e de exterioridade. Mais ainda, tentou mensurar os estados psicológicos por meio de uma suposta grandeza, não percebendo que, quando se trata de estados interiores, somente podemos falar, com propriedade, de uma intensidade pura e qualitativa. Assim, tanto a psicofísica quanto seu fundamento, o determinismo psicológico, não distinguiram a realidade espacial - extensiva e quantitativa das coisas exteriores - da realidade temporal intensiva, interna e qualitativa dos estados psicológicos.

\section{A CONFUSÃO ENTRE TEMPO E ESPAÇO NA ORIGEM DA LIBERDADE COMO UM PROBLEMA}

Na raiz do problema da liberdade está a confusão que se faz entre tempo e espaço quando não se percebe que os estados psicológicos e toda vida psíquica são de natureza temporal e não espacial. A partir dessa confusão, tem-se a representação de um eu superficial e de uma multiplicidade quantitativa dos estados da consciência porque se concebe a vida psíquica existindo no espaço e representada em um tempo espacial.

Os pressupostos do determinismo psicológico, na condição de ciência, foram levantados sobre uma base filosófica comum na qual encontramos como ideia central o conceito de

5 - "E, de fato, é a concepção do Eu como uma associação de estados psíquicos justapostos e nitidamente diferenciáveis entre si que se vincula à idéia determinista do psicológico" (LEOPOLDO E SILVA, 1994, p. 158). 
Tempo Homogêneo ou tempo espacial. Esse conceito surge da aplicação imprópria de noções como quantidade, extensão e espaço à concepção do tempo psíquico, deformando o tempo-qualidade vivido pelo eu, transformando-o no tempo-quantidade representado pelo espaço. Tal deformação, no fundo, ocorre porque se confunde a verdadeira duração da psique com sua representação simbólica, ou seja, substitui-se o tempo pelo espaço. Esse tempo homogêneo pode ser definido como um misto de tempo e espaço. A duração homogênea não é a verdadeira duração, mas um conceito híbrido, formado por meio da representação espacial que introduz seus cortes descontínuos na sucessão interna, heterogênea e contínua da duração psicológica. Bergson (1988, p. 73) explica como se processa essa confusão entre tempo e espaço:

\begin{abstract}
Mas familiarizados com esta última idéia (espaço), e obsessionados até por ela, introduzimo-la sem saber na nossa representação da sucessão pura; justapomos nossos estados da consciência de maneira a percepcioná-los simultaneamente, não já um no outro, mas um ao lado do outro; em resumo, projetamos o tempo no espaço, exprimimos a duração pela extensão, e a sucessão toma para nós a forma de uma linha contínua, ou de uma cadeia, cujas partes se tocam sem se penetrar.
\end{abstract}

0 tempo-quantidade (ou duração homogênea) é apresentado como um meio homogêneo em que os fatos da consciência se alinham e se justapõem formando uma multiplicidade quantitativa e em que cada estado separadamente se sucede um após o outro, sendo assim, é uma representação absolutamente distinta da verdadeira duração. Quando definimos o tempo dessa forma, o que estamos definindo na realidade é o espaço e a verdadeira duração que não tem a menor relação com o espaço. Conforme Hude (1990, p. 136, tradução nossa): "Esta forma de tempo é apenas uma representação da nossa intuição do tempo em termos de espaço".

0 tempo homogêneo tem sua origem numa "endosmose entre o interno e o externo" (PRADO JR, 1989, p. 99). A confusão é bilateral. De um lado, ocorre uma aparente temporalização do espaço, por meio da ilusão de que possa ocorrer uma sucessão num meio homogêneo; fato impossivel porque qualquer sucessão somente ocorre no tempo e para a consciência. A ilusão da existência de sucessão num meio homogêneo surge porque inventamos um espaço invadido pelo tempo, sobre o qual podemos justapor quantidades, esquecendo-se do ato essencial do espírito que realiza essa justaposição. De outro, ocorre uma espacialização do tempo interno invadido pelo modo de ser do que é externo, dando origem, assim, à duração homogênea. A duração interna representada como homogênea surge exatamente

6 - "Cette forme du temps n'est qu'une représentation de notre intuition du temps en termes d'espace". 
dessa troca entre a exterioridade e a interioridade. 0 que possibilita esse movimento de endosmose entre o tempo puro e o espaço puro, é a simultaneidade ${ }^{7}$, que, segundo Bergson (1988, p. 78): "[...] se poderia definir como a intersecção do tempo e do espaço". Se não houvesse simultaneidade, entre o externo e o interno, a endosmose seria impossível. Somente porque um fenômeno exterior ocorre, ao mesmo tempo que o percebo no meu interior modificando os estados da minha consciência, é que ocorre uma troca entre o espaço exterior e a duração interior. Portanto, é a simultaneidade que possibilita a endosmose espaço-temporal que produz o tempo homogêneo.

Substituímos o espaço pelo tempo e definimos o tempo interior como um meio vazio e homogêneo preenchido por uma sucessão de fatos psicológicos, da mesma maneira que concebemos o espaço como um meio vazio e homogêneo preenchido por uma coexistência. Essa homogeneidade pode ser entendida como ausência de qualidade, assim, o tempo homogêneo é um tempo sem qualidade no qual os fatos da consciência com seus contornos definidos e exteriores uns aos outros se sucederiam. Mas o tempo homogêneo não é o tempo real porque, conforme Bergson (1988, p. 71): "os fatos da consciência, ainda que sucessivos, penetram-se, e no mais simples deles pode refletir-se a alma inteira". Assim, Bergson vê o tempo real como heterogêneo e qualitativo. Se o tempo fosse homogêneo e sem qualidade, seria espaço; se definirmos espaço como homogêneo, tudo que é homogêneo é espaço, isso porque seria contraditória a existência de duas homogeneidades distintas. A confusão entre esses "dois tempos" ocorre porque movidos por interesses úteis à ação, espontaneamente substituímos o tempo verdadeiro da existência e da consciência pela ilusão do tempo da ciência e da vida cotidiana. Assim é que, introduzindo a ideia de espaço na pura duração que se chega à ideia de um tempo homogêneo e sem qualidade, usado pela ciência determinista e pela psicofísica que acabaram por tirar do tempo o essencial, isto é, a duração.

Bergson constrói sua crítica ao conceito de tempo homogêneo espacial a partir da percepção de que existem dois tipos distintos de multiplicidade, uma qualitativa e outra numérica, que levam respectivamente a duas concepções diferentes acerca da natureza do tempo: um heterogêneo e contínuo e outro homogêneo e divisivel. 0 erro do determinismo psicológico, denunciado por Bergson, foi o de ter aplicado o conceito de tempo espacial à compreensão do modo de ser do psiquismo. Bergson demonstra que o tempo homogêneo é uma noção híbrida de tempo e de espaço que surge porque se concebe a duração como homogênea, concepção que no fundo não passa de uma representação simbólica e inexata da verdadeira realidade psíquica.

7 - "Na medida em que o tempo aparece como multiplicidade numérica, medir a duração significa contar simultaneidades. Quando aplicamos este conceito de duração à vida psicológica, formamos um conjunto suscetível de decomposição e recomposição de elementos simultâneos. A simultaneidade é a noção-chave nesta endosmose entre tempo e espaço" (LEOPOLDO E SILVA, 1994, p. 136). 
Para Bergson, há o tempo real: a duração. Tempo que é mudança essencial e contínua; tempo que passa incessantemente modificando tudo e que constitui a própria essência da realidade psíquica. Todavia, não é assim que percebemos a realidade; presos aos hábitos da inteligência visando nossa ação no mundo, percebemos a realidade como estática e passível de ser fragmentada em partes que facilitam nosso agir no mundo. Temos, assim, uma concepção espacial da realidade que olha o mundo do ponto de vista da extensão. A essa visão espacial da realidade, escapa o tempo real que flui incessantemente em seu contínuo movimento, porque pensa o tempo nos moldes do espaço e, assim, concebe um tempo ilusório: o tempo espacializado, originado da confusão que inadvertidamente se faz entre tempo e espaço ${ }^{8}$. E a consciência, imbuída de representações espaciais, olha para si mesma e não se reconhece como duração pura, enxerga estados que se sucedem sem se penetrarem, não vê o eu no seu conjunto interrelacionado, esquece o passado num lugar escondido sem relação com o presente, torna as sensações e os sentimentos unidades estanques sem movimento, concebe a imobilidade como substrato da realidade. Somente da confusão entre duas realidades distintas, tempo e espaço, é que surge a ideia de tempo homogêneo, representação simbólica da verdadeira duração, sobre a qual se construiu a psicofísica e outras formas de representação do mundo que carregaram consigo esse equívoco primordial. Para evitar equívoco, é necessário distinguir o tempo do espaço e pensar a vida psíquica como essencialmente temporal. Para tanto, Bergson (1988, p. 78) esclarece que:

Há um espaço sem duração, mas onde fenômenos aparecem e desaparecem simultaneamente com os nossos estados da consciência. Há uma duração real, cujos momentos heterogêneos se interpenetram podendo cada momento aproximar-se de um estado do mundo exterior que é dele contemporâneo e separar outros momentos por efeito dessa aproximação. Da comparação destas duas realidades nasce uma representação simbólica da duração, tirada do espaço. A duração toma assim a forma ilusória de um meio homogêneo.

Assim, não podemos reduzir a noção de tempo à noção de espaço porque são realidades distintas. Logo, é necessária a depuração do misto entre tempo e espaço, da qual surgirá, de um lado, o puro espaço e, de outro, a pura duração ${ }^{9}$. Esclarecer essa confusão é um dos principais objetivos do Ensaio sobre os dados imediatos da consciência; trata-se, pois, de separar duas concepções diferentes de tempo, por um lado, o tempo-espacial utilizado pela ciência, por outro, o tempo interior, no qual vive e dura o eu. Conforme Gouhier (1961, p. 42;

\footnotetext{
8 - Bergson (1889, p. 57, ss.) trata dessa ilusão em seu Ensaio sobre os dados imediatos da consciência.

9 - Distinção que permanecerá até a formulação da duração como a própria substância das coisas, em A evolução criadora, de 1907, que tornará evidente o caráter metodológico desta distinção. Por hora, aceitemos esta distinção, que nos ajudará em muito a compreender a noção de tempo homogêneo.
} 
tradução nossa): "Para dizer a verdade, o tempo da ciência é também o tempo da linguagem, que é a expressão de uma espécie de 'senso comum' cuja vocação natural é pensar e agir. 0 tempo de existência é, ao contrário, o da duração vivida internamente e, como resultado, percebida internamente"10. Portanto, para que possamos ver nitidamente o verdadeiro tempo, devemos separar duas realidades distintas: primeiro, um espaço sem duração onde somente existe o presente absoluto e, segundo, uma duração pura onde encontramos o tempo real passando contínuo e heterogêneo, no qual ocorrem os fenômenos psíquicos.

\title{
Bergson and freedom
}

\begin{abstract}
It is intended, in this text, from the last chapter of the Essay on the immediate data of conscience, by Henri Bergson, which according to the author himself the philosophical tradition calls the problem of freedom, to present some reflections on how he intends to refute determinism, and because it is an essay that addresses a particular science, psychology, the determinism fought here is psychological. Bergson disputes with the psychophysics of his time and claims that freedom is a fact and not a problem. In summary, freedom and the problems related to it are linked to an erroneous consideration of the conception of time, which leads us to consider states of consciousness as homogeneous and separate. This conception proposes that freedom is in the self that lasts and necessity, in nature that does not last, in short, such notions are at the base of solving problems related to freedom.
\end{abstract} Keywords: Freedom. Time. Determinism. Psychology. Necessity.

\section{REFERÊNCIAS}

BERGSON, H. A evolução criadora. Tradução Adolfo Casais Monteiro. Rio de Janeiro: Opera Mundi, 1971.

BERGSON, H. Ensaio sobre os dados imediatos da consciência. Tradução de João S. Gama. Lisboa: Setenta, 1988.

BERGSON, H. Matéria e memória. São Paulo: Martins Fontes, 1990.

BERGSON, H. Oeuvres. Édition du Centenaire. 5. ed. Paris: PUF, 1991.

BERGSON, H. Textos escolhidos. Tradução Franklin Leopoldo e Silva. São Paulo: Abril Cultural, 1984. (Os Pensadores).

10 - "A dire vrai, le temps de la science est aussi le temps du langage, lequel étant l'expression d'une sorte de 'sens commun' dont la vocation naturelle est de penser pour agir. Le temps de l'existence est, au contraire, celui de la durée intérieurement vécue et, de ce fait, intérieurement perçue". 
FERRAZ JR, B. P. Presença e campo transcendental. São Paulo: Edusp, 1989.

GOUHIER, H. Bergson dans I'histoire de la pensée occidentale. Paris: Vrin, 1989.

GOUHIER, H. Bergson et le Christ des Évangiles. Paris: Arthème Fayard, 1961.

HUDE, H. Bergson. Paris: Editions Universitaires, 1990.

LEOPOLDO E SILVA, F. Bergson: intuição e discurso filosófico. São Paulo: Loyola, 1994.

PRADO JR, B. Presença e campo transcendental: consciência e negatividade na filosofia de Bergson. São Paulo: Edusp, 1989.

TROTIGNON, P. L'idée de vie chez Bergson. Paris: PUF, 1967. 